\title{
Treatments for Atopic Dermatitis
}

\author{
Adams JD*, Osvaldo Ruiter Faria Filho and Alexis Boutemy \\ Department of Pharmacology and Pharmaceutical Sciences, University of Southern California, USA
}

${ }^{*}$ Corresponding author: Adams JD, Associate Professor, Department of Pharmacology and Pharmaceutical Sciences, School of Pharmacy, University of Southern California, 1985 Zonal Avenue, Los Angeles, CA, USA, Fax: (323) 442-1681, Tel: (323) 442-1362, E-mail: jadams@pharmacy.usc.edu

Citation: Adams JD, Osvaldo Ruiter Faria Filho, Alexis Boutemy (2013) Treatments for Atopic Dermatitis. J Pharm Drug Devel 1(1): e102. doi: 10.15744/2348-9782.1.e102

Received Date: June 25, 2013 Accepted Date: July 29, 2013 Published Date: August 01, 2013

Atopic dermatitis, also known as eczema, affects about 10$20 \%$ of children in the UK and about $1-3 \%$ of adults [1]. The incidence of atopic dermatitis has increased as much as 3 fold in the past 40 years [2]. The disease is most common in children where it causes rashes, redness, sore skin, itching, dryness, blisters, bleeding, sleepless nights and more. As children become adults, many stop suffering from the disease or suffer from milder symptoms. It is rare for atopic dermatitis to first become evident in adulthood. Adults have the same symptoms as children and can also suffer from thickened, leathery skin, dry scaly patches and other problems. Children are most likely to have skin problems on the face, especially the cheeks. Adults are more likely to have skin problems on their hands, behind their elbows and knees. The skin can crack, ooze, bleed and become infected with Staphylococcus aureus and other bacteria. Healthcare professionals are especially prone to the disease. As many as $10-50 \%$ of healthcare professionals suffer from atopic dermatitis [3]. The reasons for the increase in the prevalence of atopic dermatitis are not known. The reasons healthcare professionals suffer so much form atopic dermatitis are not known. In fact, the causes of atopic dermatitis are not known.

Although there is no cure for atopic dermatitis, several drugs are used to manage the disease. These drugs help moderate symptoms so that patients can be more comfortable. Patients also have to learn how to change their lifestyles in order to avoid triggers for the disease. Triggers can include soaps, detergents, shampoos, foods, latex gloves, drugs, insects, clothing, hot water, dry conditions and more.

Topical steroids are commonly used to treat atopic dermatitis and are very effective in the majority of patients. In patients with severe symptoms, oral and injected steroids can be used. Of course, steroids are anti-inflammatory agents that moderate $\mathrm{T}$ cell function and other immune functions. Since steroids are so effective against the symptoms, there has been a lack of interest in exploring the causes of the disease. However, many patients do not get effective therapy from steroids or suffer from a range of steroid induced adverse effects. These problems include infections, cataracts, glaucoma, hypertension, osteoporosis, weight gain, stretch marks, spider veins, nausea and tachyphylaxis. In addition, some patients become allergic to the creams and ointments that are the vehicles for topical steroids. These patients suffer from aggravation of their rashes when they use steroids.

Many alternative drugs are available for the disease including cyclosporine, interferon gamma, mycophenolatemofetil, pimecrolimus and tacrolimus. These drugs are all immunosuppressants and have many adverse effects, such as infections [4]. Cyclosporine can damage the kidneys. Some patients are allergic to interferon gamma. Mycophenolate mofetil has many adverse effects including nausea, vomiting and bone marrow suppression. Pimecrolimus and tacrolimus increase skin cancer, photosensitivity and cannot be used in pregnancy. Emollients and moisturizers are very important in the therapy of the disease and can help prevent flare ups. In addition, phototherapy and cold compresses are used in some

In terms of alternative therapies, patients are uniformly warned against them. Alternative therapies are reportedly either ineffective or dangerous. For instance, borage oil and evening primrose oil have been found to be ineffective. There have been several warnings against Chinese herbal products that can be toxic. Some patients were advised to apply chamomile tea to their skin. As with any plant product, some people become allergic to the tea and develop rashes.

There is a need for safe and effective alternative therapies for atopic dermatitis. Since most alternative therapies are plant medicines, this always raises the possibility of allergenicity. Yet many traditional medical practices have medicines for atopic dermatitis, including Chinese and American Indian traditional medicine. Perhaps these traditions can provide new leads for the treatment of atopic dermatitis.

\section{References}

1. McAleer MA, Flohr C, Irvine AD (2012) Management of difficult and severe eczema in childhood. BMJ 345: e4770.

2. Dempster J, Jani B, Daly T (2011) Managing eczema in children - a treatment update. J Fam Pract 60: 660-668. 
3. Ibler KS, Jemec GB, Flyvholm MA, Diepgen TL, Jensen A, et al. (2012) Hand eczema: prevalence and risk factors of hand eczema in a population of 2274 healthcare workers. Contact Dermatitis 67: 200-207.
4. (2013) Drug Facts and Comparisons. Wolters Kluwer Health, Alphen aan den Rijn, Netherlands.

\footnotetext{
Submit your next manuscript to Annex Publishers and benefit from:

> Easy online submission process

> Rapid peer review process

> Online article availability soon after acceptance for Publication

> Open access: articles available free online

> More accessibility of the articles to the readers/researchers within the field

> Better discount on subsequent article submission

Submit your manuscript at

http://www.annexpublishers.com/paper-submission.php
} 